\title{
Rheological Properties, Dissolution Kinetics, and Ocular Pharmacokinetics of Loteprednol Etabonate (Submicron) Ophthalmic Gel 0.38\%
}

\author{
Megan E. Cavet, ${ }^{1}$ Shellise Glogowski, ${ }^{2}$ Ezra R. Lowe, ${ }^{3}$ and Eric Phillips ${ }^{4}$
}

\begin{abstract}
Purpose: To evaluate rheological properties, in vitro dissolution, and in vivo ocular pharmacokinetics of loteprednol etabonate (LE) (submicron) ophthalmic gel $0.38 \%$.

Methods: The viscosity of the LE gel $0.38 \%$ formulation was measured with a controlled stress rheometer. Dissolution kinetics were evaluated in a fixed-volume and flow-through assay. Rabbits received a single instillation of LE (submicron) gel $0.38 \%$ (both eyes), and concentrations of LE in ocular tissues were determined through $24 \mathrm{~h}$ by liquid chromatography with tandem mass spectrometry. Where indicated, comparators included micronized LE gel $0.38 \%, 0.5 \%$ (Lotemax ${ }^{\circledR}$ gel), and $0.75 \%$.

Results: LE (submicron) gel $0.38 \%$ exhibited shear-thinning characteristics similar to LE gel $0.5 \%$ with nearly identical yield stress. LE (submicron) gel $0.38 \%$ released 2.6-fold more LE into the dissolution medium than micronized LE gel $0.5 \%$ over $30 \mathrm{~s}$ in the fixed-volume dissolution assay, and submicron LE attained higher concentrations of dissolved LE than micronized LE gel $0.38 \%$ in the flow-through dissolution assay. In rabbits, the maximal concentration and area-under-the-curve over $24 \mathrm{~h}$ for LE in aqueous humor were 2.5- and 1.8-fold higher, respectively, for LE (submicron) gel $0.38 \%$ versus micronized LE gel $0.5 \%$ (both $P<0.001$ ). Pharmacokinetic parameters were similar for most other tissues.

Conclusions: LE (submicron) gel $0.38 \%$ demonstrated similar rheological properties to micronized LE gel $0.5 \%$ but faster dissolution, thus providing similar or higher LE concentrations in the aqueous humor, cornea, and iris-ciliary body after ocular dosing in rabbits despite a lowered concentration of drug in the formulation.
\end{abstract}

Keywords: pharmacokinetics, rheology, dissolution kinetics, loteprednol etabonate (submicron) gel $0.38 \%$, aqueous humor

\section{Introduction}

$\mathbf{T}$ OPICAL CORTICOSTEROIDS ARE effective in reducing postoperative pain and inflammation following ocular surgery and have become a standard of care. However, ophthalmic use of these drugs can be associated with adverse effects, including elevation of intraocular pressure (IOP), cataract formation with prolonged use, infections, and delayed wound healing. ${ }^{1-4}$ Loteprednol etabonate (LE) is a C-20 ester-based topical ophthalmic corticosteroid that was retrometabolically designed to undergo rapid hydrolysis into inactive metabolites after binding to the glucocorticoid receptor and exerting its anti-inflammatory effects. ${ }^{5,6}$ This results in a corticosteroid with potent anti-inflammatory activity with a reduced risk of undesirable effects. ${ }^{7,8}$

Currently marketed formulations of LE (Lotemax ${ }^{\circledR}$ brand; Bausch \& Lomb Incorporated, Rochester, NY) include a suspension, an ointment, and a gel, all with an LE concentration of $0.5 \%$ and a QID dosing regimen. Clinical studies with LE have demonstrated that it is effective when used to control pain and inflammation following cataract, refractive, and corneal transplant surgeries. ${ }^{9-19}$ Further studies have shown efficacy of LE in the treatment of inflammation associated with giant papillary conjunctivitis, ${ }^{20-22}$ seasonal allergic conjunctivitis, ${ }^{23-27}$ vernal

\footnotetext{
${ }^{1}$ Medical Affairs, Bausch + Lomb, Rochester, New York.

${ }^{2}$ Nonclinical Safety, R\&D, Bausch + Lomb, Rochester, New York.

${ }^{3}$ Clinical Pharmacology, Bausch + Lomb, Bridgewater, New Jersey.

${ }^{4}$ Pharmaceutical R\&D, Bausch + Lomb, Rochester, New York.
}

(c) Megan E. Cavet et al. 2019; Published by Mary Ann Liebert, Inc. This Open Access article is distributed under the terms of the Creative Commons Attribution Noncommercial License (http://creativecommons.org/licenses/by-nc/4.0/) which permits any noncommercial use, distribution, and reproduction in any medium, provided the original author(s) and the source are cited. 
keratoconjunctivitis, ${ }^{28}$ anterior uveitis, ${ }^{29}$ and blepharitis/ blepharokeratoconjunctivitis. ${ }^{30-33}$ LE was safe and well tolerated in these studies, with minimal impact on IOP in both vehicle and active comparator studies. ${ }^{7,8}$

Ocular delivery of ophthalmic therapeutics is challenging for a number of reasons. After instillation, the drug molecules must dissolve in the tear fluid before corneal absorption can occur. Speed of dissolution is critical, as a variety of precorneal protective mechanisms quickly and efficiently clear the surface of foreign material, including the normal blinking process, tear turnover, induced lacrimation, and tear fluid drainage through nasolacrimal channels. ${ }^{34-36}$ Drug molecules which survive these clearance mechanisms face additional physiochemical barriers to corneal penetration that are affected by drug molecule characteristics such as lipophilicity, charge, and molecule size. Due to these challenges, only $\sim 5 \%$ of a topical ophthalmic drug is estimated to penetrate the cornea and reach intraocular tissues. ${ }^{37}$

LE gel $0.5 \%$ (Lotemax ophthalmic gel $0.5 \%$ ) was designed to help address these drug delivery barriers. The vehicle in LE gel $0.5 \%$ contains polycarbophil, a polymer which provides the formulation with shear-thinning properties. On topical ocular instillation, dilution of the gel formulation with tears along with the applied shear stress of blinking have the net effect of transitioning the gel to a mucoadhesive liquid with sufficient viscosity to prolong the ocular residence time of LE and facilitate penetration into the anterior tissues. ${ }^{36,38}$

A new LE gel formulation (Lotemax SM) was recently approved by the Federal Drug Administration, in which the size of the drug particle has been reduced from a median diameter of $\sim 3-5 \mu \mathrm{m}$ in LE gel $0.5 \%$ to $\sim 0.4-0.6 \mu \mathrm{m}$, representing a $\sim 5$ - to 10 -fold reduction. The rationale for reducing the size of the LE particle in LE (submicron) gel was that it would enable faster dissolution, thereby facilitating ocular penetration. This is expected to allow for less frequent dosing which, in turn, could improve patient convenience and dosing compli- ance. In addition, the drug concentration of the submicron formulation was reduced by $24 \%$ from $0.5 \%$ to $0.38 \%$ which, together with the reduced dosing frequency, leads to an overall reduced drug exposure and, therefore, the potential for an improved safety profile compared to the $0.5 \%$ formulation.

Additional modifications were made to the excipients in the formulation to stabilize the submicron LE particles (Table 1). For instance, hypromellose was added to coat the drug particles to stabilize particle size. A common ingredient in artificial tears for dry eye, hypromellose, also has demulcent properties and thus may also help address corneal discomfort. ${ }^{39}$

This article reports the findings of preclinical studies conducted to evaluate the in vitro rheology and dissolution profile of LE (submicron) gel $0.38 \%$ and to investigate the ocular pharmacokinetics (PK) of LE following topical instillation of LE gel $0.38 \%$ in rabbits.

\section{Methods}

\section{Materials}

The LE (submicron) gel $0.38 \%$ formulation (particle median diameter $\sim 0.6 \mu \mathrm{m}$ ) and the 3 micronized gel formulations (particle median diameter $\sim 3 \mu \mathrm{m}$ ) with differing LE concentrations: $0.38 \%, 0.5 \%$ (marketed formulation; Lotemax), and $0.75 \%$ were prepared by Bausch \& Lomb Incorporated. The LE drug product was obtained in micronized form. For the LE submicron formulation, the LE was milled to yield the submicron particle size. The $0.5 \%$ and $0.75 \%$ gel formulations were identical except for LE concentration, and the two $0.38 \%$ gel formulations were identical except for LE particle size (Table 1 provides details of the activity and excipients of these formulations).

Hanks' Balanced Salt Solution (HBSS) was obtained from Gibco/Thermo Fisher Scientific (Waltham, MA); benzalkonium chloride (BAK) was from Spectrum Chemical (New

Table 1. Comparison of Submicron and Micronized Loteprednol Etabonate Formulations Evaluated

\begin{tabular}{|c|c|c|c|c|}
\hline & \multirow[b]{2}{*}{$\begin{array}{c}\text { LE (submicron) } \\
\text { gel } 0.38 \%\end{array}$} & \multicolumn{3}{|c|}{ Micronized formulations } \\
\hline & & $\begin{array}{l}L E \text { gel } \\
0.38 \%\end{array}$ & $\begin{array}{l}L E \mathrm{gel} \\
0.75 \%\end{array}$ & $\begin{array}{l}L E \text { gel } \\
0.5 \%{ }^{\mathrm{a}}\end{array}$ \\
\hline $\mathrm{LE}, \mathrm{mg} / \mathrm{g}$ & 3.90 & 3.96 & 7.44 & 5.0 \\
\hline Median particle diameter, $\mu \mathrm{m}$ & 0.6 & 2.9 & 2.7 & 2.7 \\
\hline
\end{tabular}

Excipients $\quad$ Function

\begin{tabular}{|c|c|c|c|c|c|}
\hline Disodium EDTA & Chelant/antimicrobial enhancer & + & + & + & + \\
\hline Sodium chloride & Tonicity agent & + & + & + & + \\
\hline Polycarbophil & Suspending and/or viscosity-increasing agent & + & + & + & + \\
\hline Hypromellose E4M & Suspending and/or viscosity-increasing agent & + & + & - & - \\
\hline Tyloxapol & Surfactant and/or wetting agent & - & - & + & + \\
\hline Poloxamer 407 & Surfactant and/or wetting agent & + & + & - & - \\
\hline BAK $(0.003 \%)$ & Antimicrobial preservative & + & + & + & + \\
\hline Glycerin & Tonicity agent/humectant & + & + & + & + \\
\hline Propylene glycol & Tonicity agent/humectants & + & + & + & + \\
\hline Boric acid & Buffer/antimicrobial enhancer & + & + & + & + \\
\hline $\begin{array}{l}\text { Sodium hydroxide and/ } \\
\text { or } \mathrm{HCl} \text { q.s. to } \mathrm{pH} 6.5\end{array}$ & $\mathrm{pH}$ adjuster & + & + & + & + \\
\hline
\end{tabular}

${ }^{\mathrm{a}}$ Marketed formulation (Lotemax ${ }^{\circledR}$ gel).

"+”,Indicates excipients that are identical among the formulations.

"-"'Indicates excipients absent from the respective formulations.

BAK, benzalkonium chloride; LE, loteprednol etabonate. 
Brunswick, NJ); sodium dodecyl sulfate (SDS) was sourced from Fisher Scientific (Hampton, NH); and phosphatebuffered saline (PBS) was prepared in house according to standard protocols.

\section{Assessment of in vitro rheological properties}

A controlled stress rheometer (TA Instruments AR2000 with firmware V7.20; TA instruments, New Castle, DE) with a vaned-rotor and cup was used to measure the rheological properties of 30-mL samples of LE (submicron) gel $0.38 \%$ and micronized LE gel $0.5 \%$ (Lotemax). A steadystate flow experiment was conducted by scanning the shear rate from $1,000 \mathrm{~s}^{-1}$ to $1 \times 10^{-5} \mathrm{~s}^{-1}$ (log scale, 10 points/decade) over $5 \mathrm{~min}$ with a sample period of $10 \mathrm{~s}$ at $25^{\circ} \mathrm{C}$.

Steady-state equilibrium was defined as 3 consecutive measurements within the tolerance window of $2 \%$. Rheology Advantage software V5.7.1 (TA Instruments) was used to collect data, and shear stress and the yield stress for the formulations were determined by fitting the steady-state flow data to the Herschel-Bulkley equation ${ }^{40}$ for nonNewtonian fluids. A second experiment was conducted as above evaluating the viscosity of the LE (submicron) gel $0.38 \%$ formulation before and after dilution 3:1 in HBSS at shear rates of $0.1-100 \mathrm{~s}^{-1}$.

\section{Fixed-volume dissolution assay}

The fixed-volume dissolution assay was conducted in a USP Apparatus No. 2 Varian Vankel VK 70000 Dissolution System (Agilent Technologies, Santa Clara, CA). A volume of $500 \mathrm{~mL}$ of dissolution medium (PBS with $0.45 \%$ SDS, added to increase the solubility of LE) was placed into a $1 \mathrm{~L}$ dissolution vessel. The temperature was maintained at $25^{\circ} \mathrm{C}$ and stirred at $100 \mathrm{rpm}$. The assay was conducted at a nonsink condition of $\sim 200 \%$ of saturation (ie, the amount of LE introduced into the dissolution medium was twice that needed to saturate the media).

An $18.42 \mathrm{~g}$ sample of test material [LE (submicron) gel $0.38 \%$ or micronized LE gel at $0.38 \%, 0.5 \%$, or $0.75 \%$ ] was dispensed into the dissolution media with a syringe fitted with an 18-gauge needle to ensure even dispersion of the gel. Aliquots $(\sim 1 \mathrm{~mL})$ of dissolution media were removed at predetermined times thereafter $(0.5,1,1.5,2,2.5,3,4$, $5 \mathrm{~min})$ and immediately filtered through a $0.22-\mu \mathrm{m}$ nylon syringe filter (Millex-HN; MilliporeSigma, Burlington, MA) to remove any undissolved LE drug particles. The filter size of $0.22 \mu \mathrm{m}$ was selected based on $>95 \%$ of the submicron LE particles having a diameter greater than $0.3 \mu \mathrm{m}$.

Concentrations of LE in the eluent were determined using high-pressure liquid chromatography (HPLC) system consisting of an 1100 Series HPLC (Agilent Technologies) coupled with a 1100 series photodiode array detector (Agilent Technologies), set at $244 \mathrm{~nm}$. Samples $(20 \mu \mathrm{L})$ were injected on an Alltima ${ }^{\mathrm{TM}}$ Phenyl $(4.6 \times 150,5 \mu \mathrm{m} \mathrm{mm})$ column (Grace Davison Discovery Science, Columbia, MD) and eluted using isocratic elution with 60:40 acetonitrile: $1 \%$ glacial acetic acid in water, at a flow rate of $1 \mathrm{~mL} / \mathrm{min}$. The column temperature was held at $25^{\circ} \mathrm{C}$. The calibration curve for LE ranged from 0.004 to $0.5 \mathrm{mg} / \mathrm{g}$ and was found to be linear $\left(R^{2}=0.99997\right)$. All samples analyzed fell within the calibration curve.

\section{Flow-through dissolution assay}

To simulate on-eye conditions of an $11 \mu \mathrm{L}$ tear volume, $\sim 30 \mu \mathrm{L}$ drop size and $10 \mu \mathrm{L} / \mathrm{min}$ tear flow rate, $8 \mathrm{~mL}$ aqueous suspensions of submicron LE particles at a concentration of $0.38 \%$, or micronized LE particles at a concentration of $0.38 \%$ or $0.75 \%$ were introduced into $3 \mathrm{~mL}$ of PBS with $1 \%$ BAK (added to increase the solubility of LE) $\mathrm{pH} 6.9$, at room temperature in a $25-\mathrm{mL}$ beaker and stirred with a magnetic stir bar.

To simulate tear flow on-eye, additional dissolution media (PBS pH 6.9, 1\% BAK) was pumped into the beaker using a multihead peristaltic pump at a flow rate of $10 \mathrm{~mL} / \mathrm{min}$, while simultaneously removing media from the beaker from the outflow end of the pump at the same flow rate. Aliquots $(0.5 \mathrm{~mL})$ of dissolution media were collected every $30 \mathrm{~s}$ for $3 \mathrm{~min}$ and then every minute thereafter for a total of $10 \mathrm{~min}$ and immediately filtered through a nylon $0.22-\mu \mathrm{m}$ syringe filter. Concentrations of LE in the eluent were analyzed by HPLC, as described above.

\section{Ocular pharmacokinetic study}

Male Dutch Belted rabbits $\sim 7$ to 8 months of age and weighing between 1.56 and $2.69 \mathrm{~kg}$ were obtained from Covance Research Products. All in-life procedures were conducted at PharmOptima (Portage, MI) according to the Association for Research in Vision and Ophthalmology statement for the Use of Animals in Ophthalmic and Vision Research and the Institute of Laboratory Animal Resources Guide for the Care and Use of Laboratory Animals. The protocol was reviewed and approved by the Institutional Animal Care and Use Committee of the test facility before the start of the study.

A comprehensive health assessment, including an ophthalmic examination (including slit lamp biomicroscopy), was performed on both eyes of study animals before inclusion into the study to verify that there were no preexisting ophthalmic abnormalities that would interfere with the outcome of the study. Animals were randomly assigned to 1 of 4 study groups of 27 animals each using a random number generator. On the day of dosing, $35 \mu \mathrm{L}$ of the assigned test formulation [LE (submicron) gel $0.38 \%$, micronized LE gel 0.38\%, micronized LE gel 0.5\% (Lotemax), or micronized gel $0.75 \%$ ] was instilled into the lower conjunctival sac of each eye of each rabbit using a calibrated Gilson M-50 positive displacement pipette. Immediately after dosing, the eyelids were gently held closed for several seconds to facilitate even distribution of the test substance over the surface of the eye and to minimize runoff.

At predetermined time intervals $(5 \mathrm{~min}, 15 \mathrm{~min}, 30 \mathrm{~min}$, and $1,2,4,8,12$, and $24 \mathrm{~h}$ ) after dosing, animals $[n=3$ per group ( 6 eyes) per collection time] were euthanized by intravenous overdose of sodium pentobarbital, and ocular tissues were collected from each eye. Tear fluid (collected using Schirmer tear strips), bulbar conjunctiva, and aqueous humor (collected using a needle and syringe) were collected in situ, whereas the cornea and iris/ciliary body (ICB) were collected once the eyes had been enucleated and snap frozen on dry ice. All samples were stored at $-80^{\circ} \mathrm{C}$ until shipment to Bausch \& Lomb Incorporated for bioanalysis.

Concentrations of LE in the ocular fluids/tissues were determined by liquid chromatography with tandem mass 
spectrometry (LC-MS/MS). The HPLC system consisted of Shimadzu LC-20ADXR pumps and a CBM-20A controller (Shimadzu Scientific Instruments, Inc.). The autosampler was a CTC PAL from LEAP technologies. A Gemini C6phenyl $(4.6 \times 150 \mathrm{~mm}, 5 \mu \mathrm{m})$ column (Phenomenex) was used for the chromatography. A triple quad mass spectrometer AB SCIEX API 5500 (Applied Biosystems) with a TurboIonSpray source in Selective Reaction Monitoring mode was used.

A variable amount of 1:1 acetonitrile: water was added to all the fluid/tissue samples except the aqueous humor using a Tecan Freedom EVO 150 (Tecan Group Ltd.). The volume of solvent was adjusted for each sample based on the individual sample weight to ensure a constant matrix concentration for all samples, standards, and quality control samples. All samples were sonicated and vortexed before transferring an aliquot to a 96-well sample plate along with the internal standard for analysis, ${ }^{2} \mathrm{H}_{5}$-LE in solvent. Aqueous humor samples were subject to protein precipitation by the addition of acetonitrile directly to a 96-well plate containing internal standard. Two sets of calibration standards (at a minimum of 8 concentration levels), 3 quality controls (prepared by adding known amounts of LE to the relevant rabbit tissue extract from untreated animals), and appropriate blanks were included in each bioanalytical run.

The lower limit of quantitation for the ocular tissues ranged from $0.0001 \mu \mathrm{g} / \mathrm{mL}$ (aqueous humor) to $0.0125 \mu \mathrm{g} / \mathrm{g}$ (tear fluid). All samples above the upper limit of quantitation were further diluted $100 \times$ with 1:1 acetonitrile: water for reanalysis.

\section{Data analysis}

Areas under the curves (AUC) for dissolved LE in the fixedvolume dissolution assay were determined using GraphPad Prism (GraphPad Software, La Jolla, CA). Analysis of the composite concentration versus time data from the rabbit PK study was performed using noncompartmental methods in WinNonlin Professional ${ }^{\circledR}$ (version 5.3; Pharsight Corporation, St. Louis, MO). The maximum concentration $\left(C_{\max }\right)$ was determined directly from the concentration versus time profiles.

$C_{\max }$ values were analyzed using the Shapiro-Wilk and Bartlett tests to determine that there was normal distribution and equal variance among the dataset. Data were then analyzed directly or, if needed, following Box-Cox transformations $^{41,42}$ using a 1-way ANOVA-Dunnett's test (JMP 11; SAS Institute, Cary, NC). The area under the concentration versus time curve $\left(\mathrm{AUC}_{0-24 \mathrm{~h}}\right)$ for each test formulation and corresponding standard error estimates were calculated using the linear trapezoid method and compared using Welch's $t$-test as demonstrated by Schoenwald et al. ${ }^{43}$ and Tang-Liu \& Burke ${ }^{44}$ using Microsoft Excel (2010).

Differences were considered statistically significant when the calculated $P$ value was less than or equal to 0.05 . Samples were considered to be outliers and therefore excluded from $C_{\max }$ and AUC calculations if concentration values were below the limit of quantitation and at least 10fold below the median or if sample concentration values were more than 10 -fold above the median concentration.

\section{Results}

\section{Rheological characteristics}

As expected, the LE (submicron) gel $0.38 \%$ formulation had nearly identical rheological characteristics as the micronized LE gel $0.5 \%$ formulation. The viscosity of the LE (submicron) gel $0.38 \%$ and micronized LE gel $0.5 \%$ ranged from 0.102 Pa.s [102 centipoises (cps)] and 0.059 Pa.s (59 cps) at a high shear rate of $100 \mathrm{~s}^{-1}$ to $\sim 3 \times 10^{6} \mathrm{~Pa} . \mathrm{s}$ $\left(3 \times 10^{3} \mathrm{cps}\right)$ and $8 \times 10^{6} \mathrm{~Pa}$.s $\left(8 \times 10^{3} \mathrm{cps}\right)$ at the lowest shear rate the instrument could measure, respectively. The shearthinning behavior of the LE (submicron) $0.38 \%$ gel and micronized LE $0.5 \%$ gel formulations is shown in Fig. 1A as a plot of viscosity as a function of applied shear stress.

At low shear stress, the gel was a semisolid and viscosity could not be measured. Beyond the yield stress, or the point at which the formulation converts from a semisolid to a liquid (2 Pa.s for LE $0.38 \%$ and 4 Pa.s for LE 0.5\%), the viscosity of each formulation rapidly decreased as the shear rate increased, such that at higher shear stresses the viscosity of both formulations was low (0.1-0.5 Pa.s). The viscosity of the LE (submicron) $0.38 \%$ formulation at a given shear rate also decreased after dilution of 3:1 with HBSS (to simulate the effect of dilution with tears on eye) as shown in Fig. 1B.
FIG. 1. Rheology characteristics of LE (submicron) gel $0.38 \%$. (A) Shear-thinning behavior of LE gel $0.38 \%$ compared to micronized LE gel $0.5 \%\left(\right.$ Lotemax $\left.^{\circledR}\right)$. Viscosity was determined at increasing shear stress; arrows show the yield stress for LE (submicron) gel (2 Pa.s) and Lotemax gel (4 Pa.s). (B) Viscosity of LE gel $0.38 \%$ before and after dilution with saline. Viscosity of LE gel $0.38 \%$ was determined at increasing shear rate before and after dilution 3:1 in Hank's buffered saline solution. LE, loteprednol etabonate.
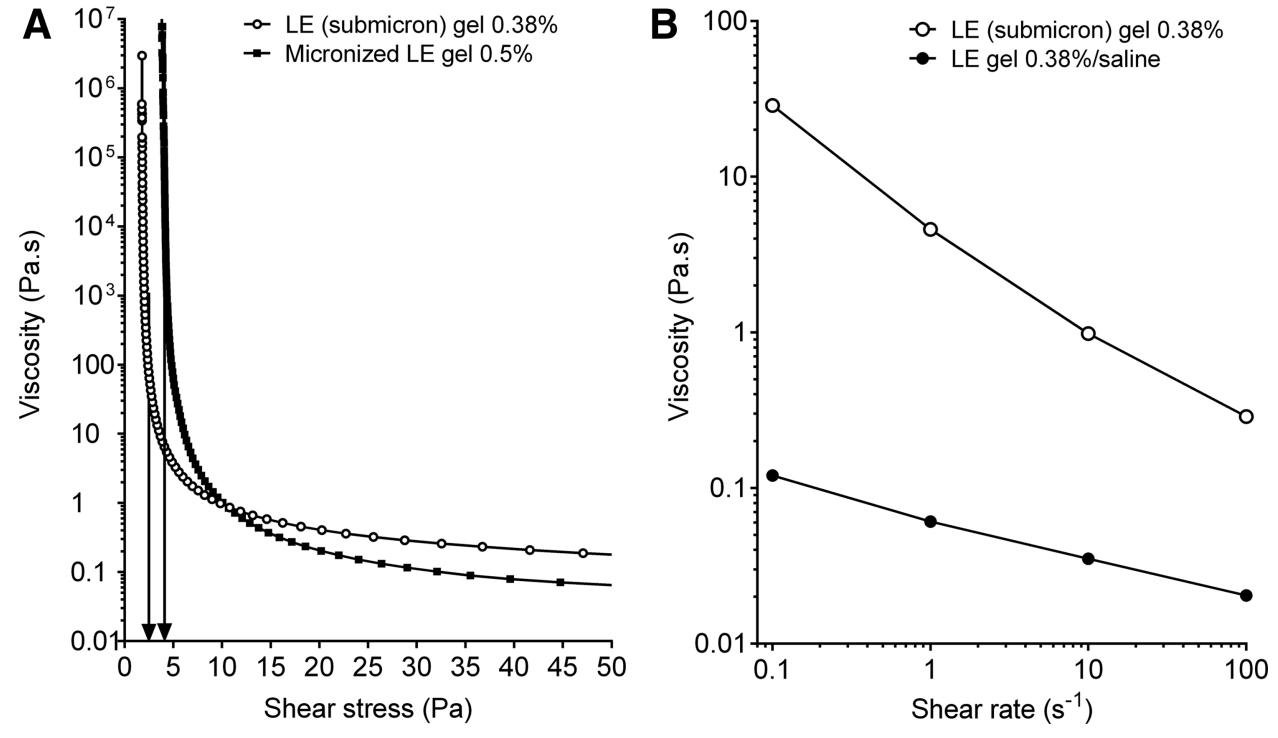


\section{In vitro dissolution}

Figure $2 \mathrm{~A}$ presents the in vitro dissolution profile of LE (submicron) gel $0.38 \%$ and that of micronized LE gel $0.38 \%, 0.5 \%$, and $0.75 \%$ in a fixed volume of dissolution media. The smaller LE particle size of the submicron formulation (ie, $0.6 \mu \mathrm{m}$ ) was associated with an increased rate of dissolution versus the 3 micronized drug particle concentrations.

At the first time point evaluated, namely $30 \mathrm{~s}$, the concentration of LE dissolved following introduction of the LE (submicron) gel $0.38 \%$ formulation was 3.4-, 2.6-, and 1.6fold higher, respectively, than concentrations of LE dissolved following introduction of the micronized $0.38 \%$, $0.5 \%$, and $0.75 \%$ gel formulations indicating an increased rate of dissolution with the smaller particle formulation. The $\mathrm{AUC}_{0-5 \min }$ for dissolved LE was 239, 151, 188, and $238 \mu \mathrm{g} \cdot \mathrm{min} / \mathrm{mL}$ for LE (submicron) gel $0.38 \%$ and $\mathrm{mi}-$ cronized LE gel $0.38 \%, 0.5 \%$, and $0.75 \%$, respectively.

Results of the flow-through dissolution assay demonstrated that at an equivalent concentration $(0.38 \%)$, introduction of an aqueous suspension of submicron LE particles into the dissolution vessel resulted in a higher peak concentration of dissolved LE compared to that following introduction of an aqueous suspension of micronized particles, again supportive of an increased dissolution rate $\left(C_{\max }\right.$ of 72 and $65 \mu \mathrm{g} / \mathrm{mL}$; respectively; Fig. 2B). Compared to LE (submicron) gel $0.38 \%$, doubling the concentration of the micronized LE particles introduced from $0.38 \%$ to $0.75 \%$ did not increase the $C_{\max }$ for dissolved LE which was $66 \mu \mathrm{g} / \mathrm{mL}$ for the micronized LE particles $0.75 \%$.

\section{Ocular pharmacokinetics}

PK parameters $\left[C_{\max }, T_{\max }\right.$, and $\left.\mathrm{AUC}_{(0-24 \mathrm{~h})}\right]$ for $\mathrm{LE}$ in ocular tissues following ocular instillation of LE (submicron) gel $0.38 \%$ and the micronized comparators, LE gels $0.38 \%, 0.5 \%$, and $0.75 \%$ are presented in Table 2 . In the

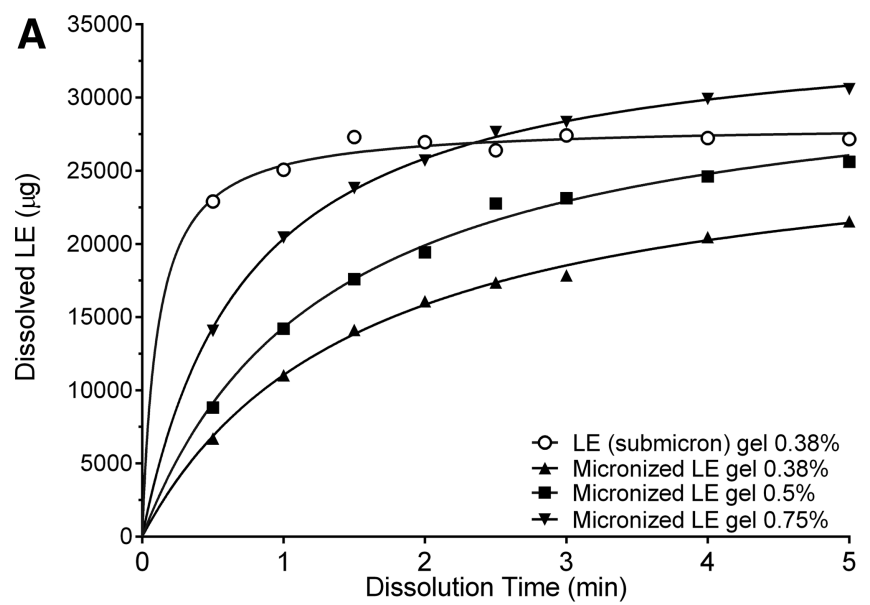

aqueous humor, the $C_{\max }$ and $\mathrm{AUC}_{0-24 \mathrm{~h}}$ for $\mathrm{LE}$ after instillation of LE (submicron) gel $0.38 \%$ were both significantly greater (2.5- and 1.8-fold, respectively) compared to LE gel $0.5 \%(P<0.001)$. The $\mathrm{AUC}_{0-24 \mathrm{~h}}$ for the bulbar conjunctiva was significantly lower (2.8-fold) with LE (submicron) gel $0.38 \%$ compared to LE gel $0.5 \%$ $(P=0.0091)$.

The $C_{\max }$ and $\mathrm{AUC}_{0-24 \mathrm{~h}}$ were similar between LE (submicron) gel $0.38 \%$ and LE gel $0.5 \%$ for the remaining tissues (all $P>0.05$ ). The $C_{\max }$ and $\mathrm{AUC}_{0-24 \mathrm{~h}}$ for micronized LE gel $0.38 \%$ and LE gel $0.75 \%$ in the ocular tissues evaluated were similar to those for LE gel $0.5 \%$, with observed differences in exposure being less than proportional to dose, except for the $\mathrm{AUC}_{0-24 \mathrm{~h}}$ for micronized $\mathrm{LE}$ gel $0.38 \%$ in tears, which was 3 -fold lower $(P=0.0076)$.

Concentration versus time profiles for LE in ocular tissues following a single topical ocular instillation of LE (submicron) gel $0.38 \%$ and micronized LE gel $0.5 \%$ are presented in Fig. 3. LE was detected in all ocular tissues for both formulations within $5 \mathrm{~min}$ of dosing, and maximum concentrations were achieved within $1 \mathrm{~h}$ of instillation (Fig. 3). Measurable concentrations of LE were present for up to $24 \mathrm{~h}$ in all tissues except the aqueous humor for which concentrations were detected for up to $12 \mathrm{~h}$.

\section{Discussion}

Results of this study demonstrate that the new LE (submicron) gel $0.38 \%$ formulation retains the rheological characteristics of LE gel $0.5 \%$ while exhibiting faster dissolution in vitro. Ocular instillation of LE (submicron) gel $0.38 \%$ also resulted in increased or similar penetration of LE into the anterior segment ocular tissues (cornea, aqueous humor, and ICB) of rabbits after a single dose.

While topical corticosteroids are a standard of care for managing inflammation following ocular surgery or inflammation in association with ocular disease, drug delivery

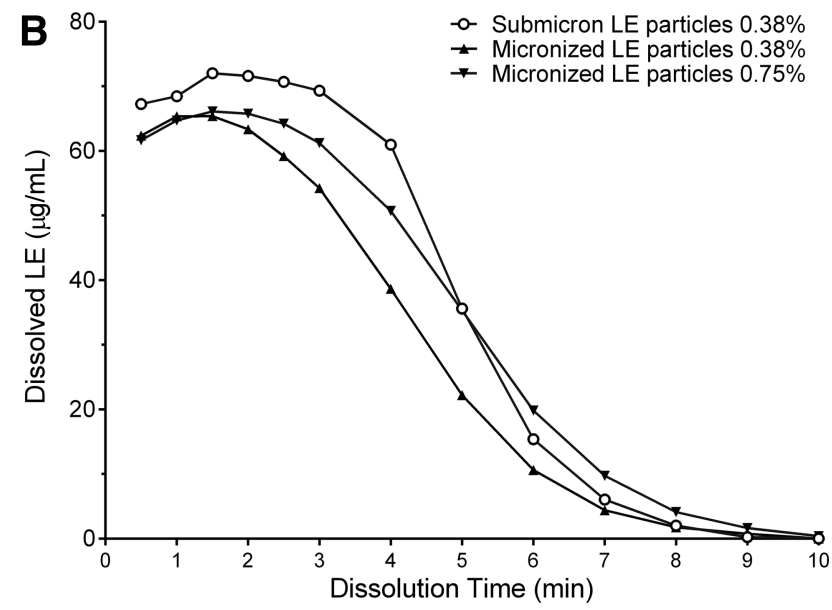

FIG. 2. Dissolution kinetics of submicron LE drug particles. (A) Fixed-volume dissolution of LE for LE (submicron) $0.38 \%$ gel and LE micronized gel at various concentrations. An $18.42 \mathrm{~g}$ sample of LE (submicron) gel $0.38 \%$ or micronized LE gel $0.38 \%, 0.5 \%$ (Lotemax), or $0.75 \%$ was added to a fixed volume of dissolution medium, and the concentration of dissolved LE was determined up to 5 min thereafter. (B) Flow-through dissolution of submicron LE particles compared to micronized LE particles. Aqueous suspensions $(8 \mathrm{~mL})$ of LE particles at a concentration of $0.38 \%$ or micronized LE particles at a concentration of $0.38 \%$ or $0.75 \%$ were introduced into a $3 \mathrm{~mL}$ sample of dissolution media (PBS pH $6.9,1 \%$ BAK); additional dissolution media was then pumped through the mixture at a flow rate of $10 \mathrm{~mL} / \mathrm{min}$. Dissolved LE was determined from samples taken from the outflow over 10 min. BAK, benzalkonium chloride; PBS, phosphate-buffered saline. 
Table 2. Ocular Pharmacokinetic Parameter Values for loteprednol Etabonate Following a Single Topical Ocular Instillation of LE (Submicron) Gel 0.38\% Compared to Micronized LE Formulations in Rabbits

\begin{tabular}{|c|c|c|c|c|c|c|}
\hline \multirow[b]{2}{*}{ Tissue $^{\mathrm{a}}$} & \multirow[b]{2}{*}{ Formulation } & \multicolumn{2}{|c|}{$\mathrm{C}_{\max }(\mu g / g)$} & \multicolumn{2}{|c|}{$A U C_{(0-24 h)}(\mu g \cdot h / g)$} & \multirow[b]{2}{*}{$\mathrm{T}_{\max }(h)$} \\
\hline & & Mean (SD) & $\begin{array}{l}\mathrm{P} \text { vs. } L E \\
\text { gel } 0.5 \%\end{array}$ & Mean $(S E)$ & $\begin{array}{l}\mathrm{P} \text { vs. } L E \\
\text { gel } 0.5 \%\end{array}$ & \\
\hline \multirow{4}{*}{$\begin{array}{l}\text { Tear } \\
\text { fluid }\end{array}$} & LE (submicron) $0.38 \%$ & $614(691)$ & 0.98 & $260(49.2)$ & 0.057 & 0.083 \\
\hline & Micronized LE $0.38 \%$ & $201(269)$ & 0.71 & $157(26.4)$ & $0.0076^{*}$ & 0.083 \\
\hline & Micronized LE $0.5 \%$ & $871(942)$ & - & $483(96.6)$ & - & 0.25 \\
\hline & Micronized LE $0.75 \%$ & $673(1,020)$ & 1.00 & $384(101.0)$ & 0.50 & 0.25 \\
\hline \multirow{4}{*}{$\begin{array}{l}\text { Bulbar } \\
\text { conjunctiva }\end{array}$} & LE (submicron) $0.38 \%$ & $12.0(12.7)$ & 0.94 & $33.5(4.3)$ & $0.0091 *$ & 0.083 \\
\hline & Micronized LE $0.38 \%$ & $78.7(102)$ & 0.30 & $55.0(10.6)$ & 0.066 & 0.25 \\
\hline & Micronized LE $0.5 \%$ & $16.4(19.7)$ & - & $95.0(16.7)$ & - & 0.25 \\
\hline & Micronized LE $0.75 \%$ & $22.4(31.0)$ & 0.97 & $96.6(18.0)$ & 0.95 & 0.25 \\
\hline \multirow[t]{4}{*}{ Cornea } & LE (submicron) $0.38 \%$ & $3.74(1.24)$ & 0.10 & $11.7(2.34)$ & 0.52 & 0.083 \\
\hline & Micronized LE $0.38 \%$ & $2.26(0.980)$ & 0.99 & $7.32(1.86)$ & 0.38 & 0.25 \\
\hline & Micronized LE $0.5 \%$ & $2.38(1.01)$ & - & $9.71(1.91)$ & - & 0.083 \\
\hline & Micronized LE $0.75 \%$ & $2.78(1.09)$ & 0.86 & $11.7(2.09)$ & 0.49 & 0.083 \\
\hline \multirow{4}{*}{$\begin{array}{l}\text { Aqueous } \\
\text { humor }^{b}\end{array}$} & LE (submicron) $0.38 \%$ & $0.0281(0.00665)$ & $0.0091 *$ & $0.0421(0.00247)$ & $0.0005^{*}$ & 1 \\
\hline & Micronized LE $0.38 \%$ & $0.0135(0.00313)$ & 0.50 & $0.0183(0.00107)$ & 0.25 & 0.5 \\
\hline & Micronized LE $0.5 \%$ & $0.0112(0.00586)$ & - & $0.0228(0.00349)$ & - & 0.5 \\
\hline & Micronized LE $0.75 \%$ & $0.0190(0.0273)$ & 1.00 & $0.0282(0.00382)$ & 0.31 & 0.25 \\
\hline \multirow{4}{*}{$\begin{array}{l}\text { Iris/ciliary } \\
\text { body }\end{array}$} & LE (submicron) $0.38 \%$ & $0.165(0.0793)$ & 0.20 & $0.338(0.0314)$ & 0.97 & 0.25 \\
\hline & Micronized LE $0.38 \%$ & $0.126(0.0758)$ & 0.52 & $0.299(0.0335)$ & 0.37 & 0.25 \\
\hline & Micronized LE $0.5 \%$ & $0.102(0.118)$ & - & $0.385(0.0841)$ & - & 0.083 \\
\hline & Micronized LE $0.75 \%$ & $0.255(0.311)$ & 0.18 & $0.491(0.0586)$ & 0.32 & 0.25 \\
\hline
\end{tabular}

$* P<0.05$ compared to LE gel $0.5 \%$.

${ }_{n}{ }_{n}=5-6$ eyes per group per time point.

${ }^{\mathrm{b}}$ For aqueous humor, the relevant units for $C_{\max }$ and $\mathrm{AUC}_{0-24 \mathrm{~h}}$ are $\mu \mathrm{g} / \mathrm{mL}$ and $\mu \mathrm{g} \cdot \mathrm{h} / \mathrm{mL}$, respectively.

$\mathrm{AUC}_{0-24 \mathrm{~h}}$, mean (standard error) area under the concentration versus time curve from the time of dosing through $24 \mathrm{~h}$; $C_{\max }$, maximum mean concentration; $T_{\max }$, time $C_{\max }$ was observed.

can be hampered by the eye's protective barriers, including dilution and removal of instilled drug through normal tear dynamics and by the challenge presented by the cornea itself (lipophilicity and tight junctions of the epithelium). ${ }^{34}$ As a result, high doses and/or frequent administration are often required to achieve sufficient and sustained drug concentrations in relevant ocular tissues.

LE gel $0.38 \%$, with submicron-sized drug particles, was designed to have prolonged ocular residence time due to inclusion of polycarbophil in the formulation, combined with faster drug dissolution in the tears due to the reduced particle size. These factors were hypothesized to allow for both a reduction in drug concentration of the formulation $(0.5 \%-0.38 \%)$ and potentially less frequent dosing (QID to TID or BID), while affording similar or greater drug exposure in relevant ocular tissues.

Findings from rheology experiments confirmed that the viscoelastic properties of the LE (submicron) gel $0.38 \%$ formulation were similar to those of micronized LE gel $0.5 \%$ with nearly identical shear-thinning behavior and decreased viscosity on dilution with saline. ${ }^{36}$ This is expected since both formulations contain equivalent concentrations of the polymer polycarbophil, which confers mucoadhesive and viscoelastic properties to the formulation. ${ }^{36,45}$ At low shear stress, both gel formulations are highly viscous, which allows for existence as a non-settling semisolid at rest (in the bottle) without the need for shaking before dosing. ${ }^{36,46}$

Like LE gel $0.5 \%$, the $0.38 \%$ formulation displayed a rapid decrease in viscosity with increasing shear stress; thus the increased shear stress of squeezing the bottle during instillation causes the formulation to behave as a low-viscosity liquid for easy dispensing through the dropper tip. In addition, the transition of the formulation to a viscous liquid on dilution with saline indicates that when instilled into the eye, due to dilution with tears and the intermittently applied shear stress of blinking, LE (submicron) gel $0.38 \%$ behaves as a mucoadhesive viscous liquid, also similar to the $0.5 \%$ gel formulation. ${ }^{36}$ This characteristic of the gel formulations is important for prolonging ocular surface residence time relative to suspension formulations, while minimizing potential for stickiness and blurring. In support of the latter, there were no reports of drugrelated blurred vision, and most subjects reported no discomfort upon instillation in a Phase 3 study evaluating LE gel $0.38 \%$ for treatment of postsurgical inflammation and pain. ${ }^{47}$

Dissolution is a prerequisite to ocular penetration. Reducing the particle size of a drug results in an increase in total surface area of the drug particles and, thus, is an effective way to enhance drug dissolution rate. ${ }^{48}$ The submicron LE particles evaluated in this study had an $\sim 5$-fold smaller median diameter than the micronized LE particles, resulting in an $\sim 5$-fold greater total surface area compared to an equivalent concentration of the micronized particles.

As expected, due to the increase in available total surface area with the smaller versus larger LE particles, in both the fixed volume and flow-through dissolution assays, the observed dissolution rate of the submicron LE particles was greater compared with the micronized LE particles at the equivalent concentration. Indeed, it is possible that the fold increase in dissolution rate would have been even more apparent had sampling been possible earlier than the earliest 


\section{A Tears}

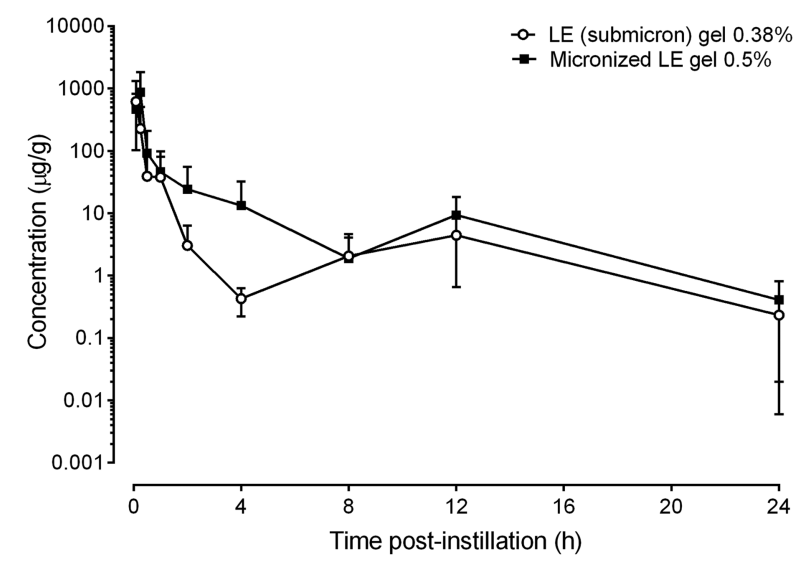

C Cornea

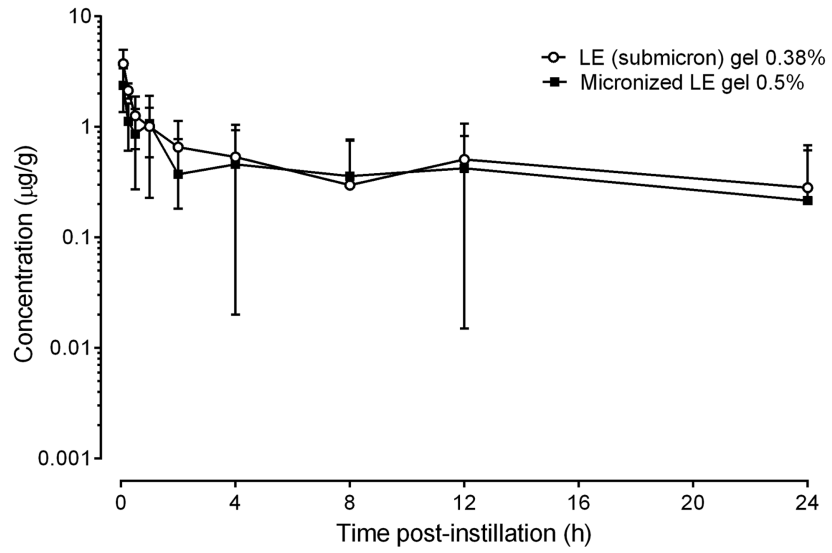

E Iris-ciliary body

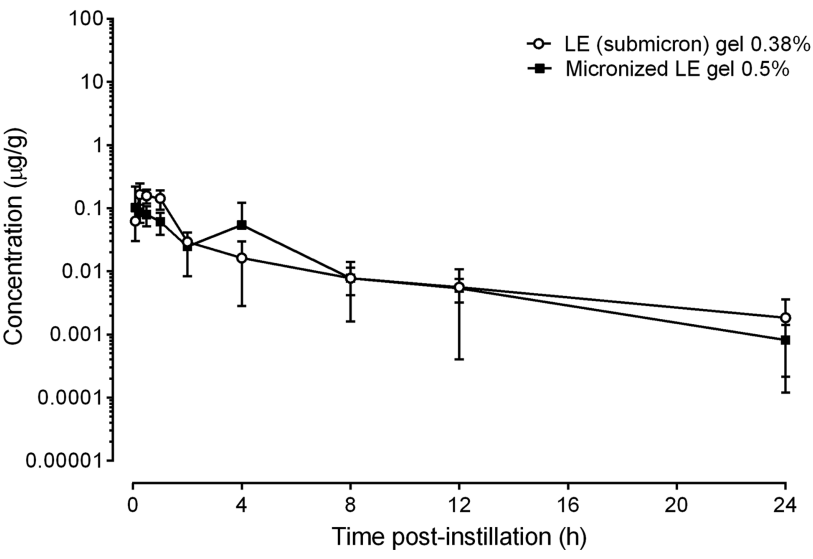

B Conjunctiva

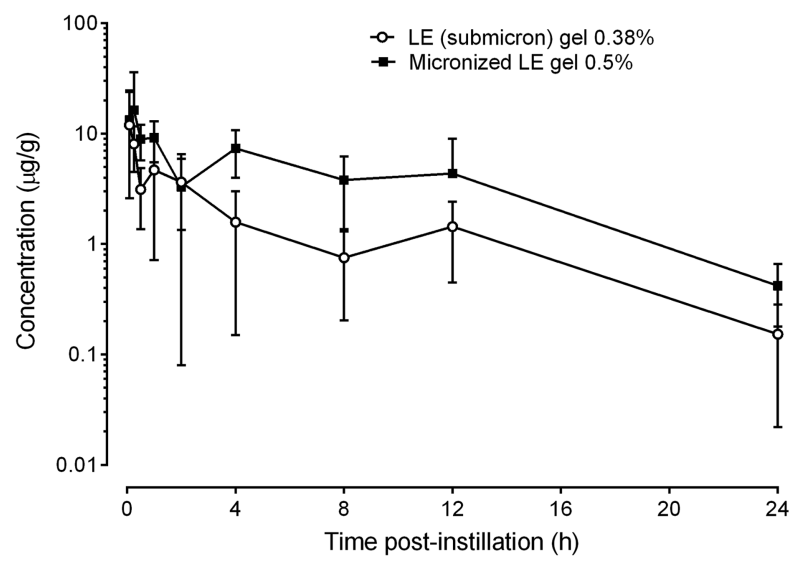

D Aqueous humor

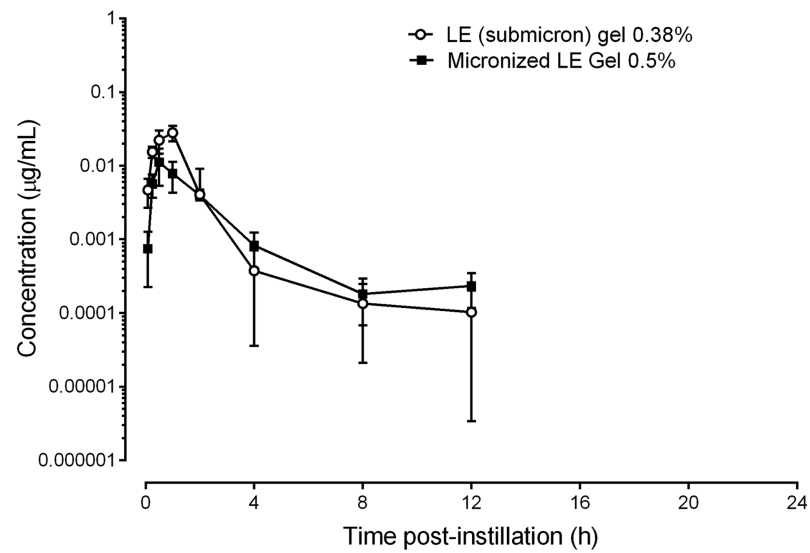

FIG. 3. Pharmacokinetic profile of LE (submicron) gel $0.38 \%$ in rabbits. Mean (SD) LE concentrations in (A) tear fluid, (B) bulbar conjunctiva, (C) cornea, (D) aqueous humor, and (E) iris/ciliary body of rabbits after a single ocular instillation of LE (submicron) gel $0.38 \%$ or micronized LE gel $0.5 \%$ (Lotemax). Error bars represent standard deviations; $n=4-6$ eyes per group per time point. Note that for the aqueous humor, LE was detected in 1 out of the 6 eyes at the $24 \mathrm{~h}$ time point for LE gel $0.5 \%$.

sampling time point in these experiments (ie, $30 \mathrm{~s}$ ), a time frame likely to reflect zero order dissolution kinetics. Furthermore, doubling the concentration of the micronized particles to $0.75 \%$ did not appear to increase dissolution compared to LE (submicron) $0.38 \%$ over the respective time frames of the 2 dissolution assays, confirming the influence of the smaller particle size on the rate of drug dissolution. On eye, the mucoadhesive properties of the gel formulation together with the faster dissolution rate of the submicron drug particles may help overcome the rapid elimination of drug by tear flow/turnover and facilitate penetration through the ocular surface. 
As a correlate to the improved dissolution with smaller LE particles, the $C_{\max }$ and $\mathrm{AUC}_{0-24 \mathrm{~h}}$ for $\mathrm{LE}$ in the aqueous humor of rabbits were significantly greater following instillation of a single topical ocular dose of LE (submicron) gel $0.38 \%$ compared to micronized LE gel $0.5 \%$. The aqueous humor $C_{\max }$ and $\mathrm{AUC}_{0-24 \mathrm{~h}}$ with $\mathrm{LE}$ (submicron) gel $0.38 \%$ also appeared to be about $50 \%$ higher than that observed with the micronized $0.75 \%$ formulation, again highlighting the impact of the reduced particle size on rate of dissolution and therefore penetration.

Maximum LE concentrations achieved in the ICB and cornea were also numerically greater following instillation of LE (submicron) gel $0.38 \%$ compared to LE gel $0.5 \%$, while the $\mathrm{AUC}_{0-24 \mathrm{~h}}$ in these tissues was similar to those for LE gel $0.5 \%$. Therefore, despite a $24 \%$ reduction in drug concentration in the formulation, LE released by LE (submicron) gel $0.38 \%$ reaches the anterior segment ocular tissues most relevant to addressing postsurgical inflammation, that is, the aqueous humor and ICB, at equivalent or higher levels than micronized LE gel $0.5 \%$. Conversely, based on the $\mathrm{AUC}_{0-24 \mathrm{~h}}$ values, LE conjunctival concentrations were significantly lower following instillation of LE (submicron) $0.38 \%$ relative to LE gel $0.5 \%$ and numerically lower in tears, consistent with greater penetration of LE through the ocular surface into the anterior chamber. Nevertheless, concentrations of LE in the conjunctiva following a single dose of LE gel $0.38 \%$ remained higher than those in all other ocular tissues.

The ocular PK parameters for LE gel $0.5 \%$ in this study agree with those from a similarly designed study, which showed that LE gel $0.5 \%$ provided prolonged exposure of LE to the ocular tissues, with ocular drug levels being highest in the conjunctiva, followed by cornea, ICB, and aqueous humor after a single $35-\mu \mathrm{L}$ instillation of drug. ${ }^{38}$ In both studies, LE was detected in all tissues for up to $24 \mathrm{~h}$, with the exception of the aqueous humor, where LE levels were detected for up to $12 \mathrm{~h}$, likely due to clearing through aqueous turnover in conjunction with esterase activity. The respective $C_{\max }$ and $\mathrm{AUC}_{(0-24 \mathrm{~h})}$ for $\mathrm{LE}$ in the previous study were $0.162 \mu \mathrm{g} / \mathrm{mL}$ and $0.282 \mu \mathrm{g} \cdot \mathrm{h} / \mathrm{mL}$ for the ICB and $0.0138 \mu \mathrm{g} / \mathrm{mL}$ and $0.0157 \mu \mathrm{g} \cdot \mathrm{h} / \mathrm{mL}$ for aqueous humor and similar to those determined in the current study for LE gel $0.5 \%$ (Table 2).

The ocular PK of a LE formulation with reduced particle size along with mucus-penetrating particle technology (LEMPP) was previously reported. ${ }^{49}$ In contrast to LE (submicron) $0.38 \%$ gel, the LE-MPP formulation evaluated was a suspension containing LE particles with a diameter in the range of $200 \mathrm{~nm}$ and coated with a mucus penetrating agent. In a study comparing the ocular PK of LE following instillation of a single 50- $\mu \mathrm{L}$ drop of LE-MPP $0.4 \%$ with that of micronized LE suspension $0.5 \%$ into rabbit's eyes, the $C_{\max }$ for LE was $\sim 3$-fold higher in ocular tissues and the aqueous humor with LE-MPP $0.4 \%$ than with the micronized LE suspension $0.5 \% .{ }^{49}$ Of note, in the current study, LE concentrations in the aqueous humor and ICB following instillation of LE (submicron) gel $0.38 \%$ appear similar to those reported following instillation of LE-MPP $0.4 \%$ both based on AUC and the $C_{\max }$. However, these apparent similarities need to be confirmed in a head-to-head study comparing the LE (submicron) gel $0.38 \%$ formulation to the LE-MPP suspension.

Currently, topical ophthalmic corticosteroids indicated for the treatment of pain and inflammation postcataract surgery have a QID dosing regimen (LE $0.5 \%$ suspension, gel, ointment, and difluprednate $0.05 \%) .^{50-53}$ The PK data presented here indicate that a reduced dosing frequency is possible with LE (submicron) gel $0.38 \%$ even with a reduced drug concentration of the formulation.

Indeed, 2 pivotal Phase 3, randomized, multicenter, vehicle-controlled clinical trials have demonstrated that LE (submicron) gel $0.38 \%$ appeared safe and effective for the reduction of inflammation and pain postcataract surgery, with a TID dosing regimen. ${ }^{47,54}$ In both studies, the numbers of subjects with complete resolution of ocular pain and anterior chamber cells (primary efficacy endpoint) were significantly higher in the LE (submicron) gel $0.38 \%$ TID dosing group compared to the vehicle group. Improvements in resolution of inflammation and pain postcataract surgery were also observed with BID dosing, despite the drug not meeting the primary efficacy endpoint in 1 study. ${ }^{47,54}$ In addition, there was minimal impact on IOP, with a total of only 4 reports of IOP elevation $\geq 10 \mathrm{~mm} \mathrm{Hg}$ in the LE (submicron) gel $0.38 \%$ BID and TID treatment groups across both studies encompassing a total of 742 LE-treated subjects. $^{47,54}$

In conclusion, the LE (submicron) gel $0.38 \%$ formulation demonstrated similar rheological properties and a higher rate of drug dissolution in vitro than the current marketed formulation, micronized LE gel $0.5 \%$. The LE (submicron) gel $0.38 \%$ formulation also provided higher or similar concentrations of LE in clinically relevant rabbit ocular tissues, including the aqueous humor and ICB, compared to micronized LE gel $0.5 \%$. These findings, together with data from clinical studies, support the concept that the antiinflammatory efficacy of LE will be maintained at a reduced concentration and with a reduced dosing frequency with LE (submicron) gel $0.38 \%$.

\section{Acknowledgments}

Writing and editorial support was provided by Adrienne Drinkwater, PhD and Judith Adams, PharmD of Churchill Communications, Maplewood, New Jersey. The authors acknowledge the expert assistance of Heleen H. DeCory, PhD, of Bausch + Lomb with content development.

\section{Author Disclosure Statement}

M.C., S.G., E.L., and E.P. are employees of Bausch Health Companies Inc. and its affiliates and are stockholders in Bausch Health Companies, Inc.

\section{References}

1. McGhee, C.N., Dean, S., and Danesh-Meyer, H. Locally administered ocular corticosteroids: benefits and risks. Drug Saf. 25:33-55, 2002.

2. Pavesio, C.E., and DeCory, H.H. Treatment of ocular inflammatory conditions with loteprednol etabonate. $\mathrm{Br}$. J. Ophthalmol. 92:455-459, 2008.

3. Pleyer, U., Ursell, P.G., and Rama, P. Intraocular pressure effects of common topical steroids for post-cataract inflammation: are they all the same? Ophthalmol. Ther. 2:5572, 2013.

4. James, E.R. The etiology of steroid cataract. J. Ocular Pharm. Ther. 23:403-420, 2007. 
5. Bodor, N., Bodor, N., and Wu, W.M. A comparison of intraocular pressure elevating activity of loteprednol etabonate and dexamethasone in rabbits. Curr. Eye Res. 11: 525-530, 1992.

6. Bodor, N. Recent advances in retrometabolic design approaches. J. Control. Release. 62:209-222, 1999.

7. Sheppard, J.D., Comstock, T.L., and Cavet, M.E. Impact of the topical ophthalmic corticosteroid loteprednol etabonate on intraocular pressure. Adv. Ther. 33:532-552, 2016.

8. Comstock, T.L., and Sheppard, J.D. Loteprednol etabonate for inflammatory conditions of the anterior segment of the eye: twenty years of clinical experience with a retrometabolically designed corticosteroid. Expert Opin. Pharmacother. 19:337-353, 2018.

9. Stewart, R., Horwitz, B., Howes, J., et al.; for the Loteprednol Etabonate Post-Operative Inflammation Study Group 1. Double-masked, placebo-controlled evaluation of loteprednol etabonate $0.5 \%$ for postoperative inflammation. J. Cataract Refract. Surg. 24:1480-1489, 1998.

10. Loteprednol Etabonate Postoperative Inflammation Study Group 2. A double-masked, placebo-controlled evaluation of $0.5 \%$ loteprednol etabonate in the treatment of postoperative inflammation. Ophthalmology. 105:1780-1786, 1998.

11. Comstock, T.L., Paterno, M.R., Singh, A., et al. Safety and efficacy of loteprednol etabonate ophthalmic ointment $0.5 \%$ for the treatment of inflammation and pain following cataract surgery. Clin. Ophthalmol. 5:177-186, 2011.

12. Rajpal, R.K., Roel, L., Siou-Mermet, R., et al. Efficacy and safety of loteprednol etabonate $0.5 \%$ gel in the treatment of ocular inflammation and pain after cataract surgery. $J$. Cataract Refract. Surg. 39:158-167, 2013.

13. Fong, R., Leitritz, M., Siou-Mermet, R., et al. Loteprednol etabonate gel $0.5 \%$ for postoperative pain and inflammation after cataract surgery: results of a multicenter trial. Clin. Ophthalmol. 6:1113-1124, 2012.

14. Holzer, M.P., Solomon, K.D., Sandoval, G.P., et al. Comparison of ketorolac tromethamine $0.5 \%$ and loteprednol etabonate $0.5 \%$ for inflammation after phacoemulsification. J. Cataract Refract. Surg. 28:93-99, 2002.

15. Lane, S.S., and Holland, E.J. Loteprednol etabonate $0.5 \%$ versus prednisolone acetate $1.0 \%$ for the treatment of inflammation after cataract surgery. J. Cataract Refract. Surg. 39:168-173, 2013.

16. Abessi, B., Brooksby, L.M., and Schultze, R.L. Comparison of efficacy of difluprednate $0.05 \%$ and loteprednol gel $0.5 \%$ after cataract surgery. Eye Contact Lens. 44:S37-S42, 2017.

17. Karimian, F., Faramarzi, A., Fekri, S., et al. Comparison of loteprednol with fluorometholone after myopic photorefractive keratectomy. J. Ophthalmic Vis. Res. 12:11-16, 2017.

18. Mifflin, M.D., Betts, B.S., Frederick, P.A., et al. Efficacy and safety of a 3-month loteprednol etabonate $0.5 \%$ gel taper for routine prophylaxis after photorefractive keratectomy compared to a 3-month prednisolone acetate $1 \%$ and fluorometholone $0.1 \%$ taper. Clin. Ophthalmol. 11:1113-1118, 2017.

19. Price, M.O., Feng, M.T., Scanameo, A., et al. Loteprednol etabonate $0.5 \%$ gel vs. prednisolone acetate $1 \%$ solution after descemet membrane endothelial keratoplasty: prospective randomized trial. Cornea. 34:853-858, 2015.

20. Bartlett, J.D., Howes, J.F., Ghormley, N.R., et al. Safety and efficacy of loteprednol etabonate for treatment of papillae in contact lens-associated giant papillary conjunctivitis. Curr. Eye. Res. 12:313-321, 1993.
21. Asbell, P., and Howes, J. A double-masked, placebocontrolled evaluation of the efficacy and safety of loteprednol etabonate in the treatment of giant papillary conjunctivitis. CLAO J. 23:31-36, 1997.

22. Friedlaender, M.H., and Howes, J. A double-masked, placebo-controlled evaluation of the efficacy and safety of loteprednol etabonate in the treatment of giant papillary conjunctivitis. Am. J. Ophthalmol. 123:455-464, 1997.

23. Dell, S.J., Shulman, D.G., Lowry, G.M., et al. A controlled evaluation of the efficacy and safety of loteprednol etabonate in the prophylactic treatment of seasonal allergic conjunctivitis. Am. J. Ophthalmol. 123:791-797, 1997.

24. Dell, S.J., Lowry, G.M., Northcutt, J.A., et al. A randomized, double-masked, placebo-controlled parallel study of $0.2 \%$ loteprednol etabonate in patients with seasonal allergic conjunctivitis. J. Allergy Clin. Immun. 102:251-255, 1998.

25. Shulman, D.G., Lothringer, L.L., Rubin, J.M., et al. A randomized, double-masked, placebo-controlled parallel study of loteprednol etabonate $0.2 \%$ in patients with seasonal allergic conjunctivitis. Ophthalmology. 106:362-369, 1999.

26. Gong, L., Sun, X., Qu, J., et al. Loteprednol etabonate suspension $0.2 \%$ administered QID compared with olopatadine solution $0.1 \%$ administered BID in the treatment of seasonal allergic conjunctivitis: a multicenter, randomized, investigator-masked, parallel group study in Chinese patients. Clin. Ther. 34:125, 2012.

27. Liu, R.F., Wu, X.X., Wang, X., et al. Efficacy of olopatadine hydrochloride $0.1 \%$, emedastine difumarate $0.05 \%$, and loteprednol etabonate $0.5 \%$ for Chinese children with seasonal allergic conjunctivitis: a randomized, vehiclecontrolled study. Int. Forum Allergy Rhinol. 7:393-398, 2017.

28. Oner, V., Turkcu, F.M., Tas, M., et al. Topical loteprednol etabonate $0.4 \%$ for treatment of vernal keratoconjunctivitis: efficacy and safety. Jpn. J. Ophthalmol. 56:312-318, 2012.

29. Loteprednol Etabonate US Uveitis Study Group. Controlled evaluation of loteprednol etabonate and prednisolone acetate in the treatment of acute anterior uveitis. Am. J. Ophthalmol. 127:537-544, 1999.

30. Chen, M., Gong, L., Sun, X., et al. A multicenter, randomized, parallel-group, clinical trial comparing the safety and efficacy of loteprednol etabonate $0.5 \% /$ tobramycin $0.3 \%$ with dexamethasone $0.1 \%$ /tobramycin $0.3 \%$ in the treatment of Chinese patients with blepharokeratoconjunctivitis. Curr. Med. Res. Opin. 28:385-394, 2012.

31. White, E.M., Macy, J.I., Bateman, K.M., et al. Comparison of the safety and efficacy of loteprednol $0.5 \%$ /tobramycin $0.3 \%$ with dexamethasone $0.1 \%$ /tobramycin $0.3 \%$ in the treatment of blepharokeratoconjunctivitis. Curr. Med. Res. Opin. 24:287-296, 2008.

32. Comstock, T.L., Paterno, M.R., Bateman, K.M., et al. Safety and tolerability of loteprednol etabonate $0.5 \%$ and tobramycin $0.3 \%$ ophthalmic suspension in pediatric subjects. Pediatr. Drugs. 14:119-130, 2012.

33. Rhee, S.S., and Mah, F.S. Comparison of tobramycin $0.3 \% /$ dexamethasone $0.1 \%$ and tobramycin $0.3 \%$ /loteprednol $0.5 \%$ in the management of blepharo-keratoconjunctivitis. Adv. Ther. 24:60-67, 2007.

34. Ghate, D., and Edelhauser, H.F. Ocular drug delivery. Expert. Opin. Drug Deliv. 3:257-287, 2006.

35. Gaudana, R., Ananthula, H.K., Parenky, A., et al. Ocular drug delivery. AAPS. J. 12:348-360, 2010.

36. Coffey, M.J., DeCory, H.H., and Lane, S.S. Development of a non-settling gel formulation of $0.5 \%$ loteprednol eta- 
bonate for anti-inflammatory use as an ophthalmic drop. Clin. Ophthalmol. 7:299-312, 2013.

37. Ananthula, H.K., Vaishya, R.D., Barot, M., et al. Bioavailability. In: Tasman W, and Jaeger EA, eds. Duane's Ophthalmology. Philadelphia: Lippincott Williams and Wilkins; 2011.

38. Glogowski, S., Lowe, E., Siou-Mermet, R., et al. Prolonged exposure to loteprednol etabonate in human tear fluid and rabbit ocular tissues following topical ocular administration of lotemax gel, 0.5\%. J. Ocular Pharmacol. Ther. 30:6673, 2014.

39. Code of Federal Regulations Title 21. Part 349.12 Ophthalmic demulcents, and Part 349.60 Labeling of ophthalmic demulcent drug products. Revised April 1, 2018. Available from: www.accessdata.fda.gov/scripts/cdrh/cfdocs/ cfcfr/CFRSearch.cfm?CFRPart=349 Accessed January 24, 2018.

40. Bird, R.B., Dai, G.C., and Yarusso, B.J. The Rheology and Flow of Viscoplastic Materials. Rev. Chem. Engineer. 1(1): 1-70, 1983.

41. Box, G.E.P., and Cox, D.R. An analysis of transformations. J. R. Stat. Soc. Series B. 26:211-252, 1964.

42. Box, G.E.P., and Hill, W. Correcting inhomogeneity of variance with power transformation weighting. Technometrics. 16:385-389, 1974.

43. Schoenwald, R.D., Harris, R.G., Turner, D., et al. Ophthalmic bioequivalence of steroid/antibiotic combination formulations. Biopharm. Drug Dispos. 8:527-548, 1987.

44. Tang-Liu, D.D., and Burke, P.J. The effect of azone on ocular levobunolol absorption: calculating the area under the curve and its standard error using tissue sampling compartments. Pharm. Res. 5:238-241, 1988.

45. Almeida, H., Amaral, M.H., Lobão, P., et al. In situ gelling systems: a strategy to improve the bioavailability of ophthalmic pharmaceutical formulations. Drug Discov. Today. 19:400-412, 2014.

46. Marlowe, Z.T., and Davio, S.R. Dose uniformity of loteprednol etabonate ophthalmic gel $(0.5 \%)$ compared with branded and generic prednisolone acetate ophthalmic suspension (1\%). Clin. Ophthalmol. 8:23-29, 2014.
47. Fong, R., Silverstein, B.E., Peace, J.H., et al. Submicron loteprednol etabonate ophthalmic gel $0.38 \%$ for the treatment of inflammation and pain after cataract surgery. $J$. Cataract. Refract. Surg. 44:1220-1229, 2018.

48. Dizaj, S.M., Vazifehasl, Z.H., Salatin, S., et al. Nanosizing of drugs: effect on dissolution rate. Res. Pharm. Sci. 10:95108, 2015.

49. Schopf, L., Enlow, E., Popov, A., et al. Ocular pharmacokinetics of a novel loteprednol etabonate $0.4 \%$ ophthalmic formulation. Ophthalmol. Ther. 3:63-72, 2014.

50. Lotemax ${ }^{\circledR}$ (ophthalmic suspension) 0.5\%. US Prescribing Information. Bridgewater, NJ: Bausch \& Lomb Incorporated; 2016.

51. Lotemax ${ }^{\circledR}$ (loteprednol etabonate ophthalmic gel) $0.5 \%$. US Prescribing Information. Bridgewater, NJ: Bausch \& Lomb Incorporated; 2016.

52. Lotemax $^{\circledR}$ (loteprednol etabonate ophthalmic ointment) 0.5\%. US Prescribing Information. Bridgewater, NJ: Bausch \& Lomb Incorporated; 2017.

53. Durezol ${ }^{\circledR}$ (difluprednate ophthalmic emulsion) $0.5 \%$. US Prescribing Information. Fort Worth, TX: Alcon Laboratories; 2017.

54. Vittitow, J.L., LoBue, T., and Martel, J., et al. Safety and efficacy of a novel submicron loteprednol etabonate gel in the treatment of inflammation and pain post-cataract surgery. Invest. Ophthalmol. Vis. Sci. 59:Abstract 2235, 2018.

Received: November 20, 2018

Accepted: February 11, 2019

Address correspondence to:

Dr. Megan E. Cavet Medical Affairs

Bausch + Lomb

1400 North Goodman Street Rochester, NY 14609

E-mail: megan.cavet@bausch.com 